\title{
Effect of Chrysin on Gene Expression and Production of MUC5AC Mucin from Cultured Airway Epithelial Cells
}

\author{
Hyun-Dae Shin, M.D., Ph.D. ${ }^{1,2 \star}$, Hyun Jae Lee, Ph.D. ${ }^{1 *}$, Md. Asaduzzaman Sikder, Ph.D. ${ }^{1}$, Su Hyun Park, \\ B.S. , Jiho Ryu, B.S. , Jang-Hee Hong, M.D., Ph.D. ${ }^{1}$, Ju-Ock Kim, M.D., Ph.D. ${ }^{3}$, Jeong Ho Seok, M.D., Ph.D. \\ Choong Jae Lee, Ph.D. ${ }^{1}$ \\ ${ }^{1}$ Department of Pharmacology, Chungnam National University School of Medicine, ${ }^{2}$ Department of Orthopedic Surgery, \\ Chungnam National University Hospital, ${ }^{3}$ Pulmonology Section, Department of Internal Medicine, Chungnam National University \\ Hospital, Chungnam National University School of Medicine, Daejeon, Korea
}

Background: We investigated whether chrysin affected MUC5AC mucin production and gene expression induced by phorbol ester (phorbol 12-myristate 13-acetate, PMA) or epidermal growth factor (EGF) from human airway epithelial cells.

Methods: Confluent NCI-H292 cells were pretreated with varying concentrations of chrysin for 30 minutes, and were then stimulated with PMA and EGF for 24 hours, respectively. MUC5AC mucin gene expression and mucin protein production were measured by reverse transcription polymerase chain reaction and enzyme-linked immunosorbent assay.

Results: Concentrations of $10 \mu \mathrm{M}$ and $100 \mu \mathrm{M}$ chrysin were found to inhibit the production of MUC5AC mucin protein induced by PMA; A concentration of $100 \mu \mathrm{M}$ chrysin also inhibited the production of MUC5AC mucin protein induced by EGF; $100 \mu \mathrm{M}$ chrysin inhibited the expression of MUC5AC mucin gene induced by PMA or EGF. The cytotoxicity of chrysin was checked by lactate dehydrogenase assay, and there was no cytotoxic effect observed for chrysin.

Conclusion: These results suggest that chrysin can inhibit mucin gene expression and the production of mucin protein by directly acting on airway epithelial cells.

Key Words: Epithelial Cells; Mucins; Chrysin

\section{Introduction}

Mucus in the airway is very important in defense against airborne chemicals, particles and pathogenic microorganisms. The protective function of airway mucus is due mainly to the viscoelastic property of mucous

Address for correspondence: Choong Jae Lee, Ph.D.

Department of Pharmacology, Chungnam National University School of Medicine, 6, Munhwa 1-dong, Jung-gu, Daejeon 301-131, Korea

Phone: 82-42-580-8255, Fax: 82-42-585-6627

E-mail: LCJ123@cnu.ac.kr

*Hyun-Dae Shin and Hyun Jae Lee equally contributed to this work.

Received: Jul. 31, 2012

Revised: Aug. 16, 2012

Accepted: Sep. 13, 2012

(a) It is identical to the Creative Commons Attribution Non-Commercial License (http://creativecommons. org/licenses/by-nc/3.0/). glycoproteins or mucins. Mucins are macromolecular glycoproteins present in the airway mucus and have peptide backbones and carbohydrate branches ${ }^{1}$. Up to now, twenty mucin (MUC) genes have been reported as coding the peptide backbone of human mucins and, among them, MUC5AC is remarkably expressed in airway goblet cells ${ }^{2,3}$. However, any abnormality in the quality or quantity of mucins not only cause altered airway physiology but may also impair host defenses often leading to serious airway pathology as exemplified in chronic bronchitis, cystic fibrosis, asthma, and bronchiectasis $^{1}$. Therefore, we suggest it is valuable to find the possible activity of controlling (inhibiting) the excess mucin secretion (production) by the components from medicinal plants that have been used for the management of airway diseases. We have tried to inves- 
tigate the possible activities of some natural products on mucin secretion from cultured airway epithelial cells. As a result of our trial, we previously reported that several natural compounds affected mucin production and/or secretion from airway epithelial cells ${ }^{4-6}$. According to traditional oriental medicine, Scutellariae Radix has been used for regulating airway allergic and inflammatory diseases ${ }^{7}$ and one of their components, chrysin, was reported to have diverse biological effects including antiinflammatory effect ${ }^{8-10}$. However, to the best of our knowledge, no other studies about potential effect of chrysin on mucin production and gene expression from airway epithelial cells have been carried out. Therefore, in this study, we examined whether chrysin affect MUC5AC mucin production and gene expression from NCI-H292 cells, a human pulmonary mucoepidermoid cell line, which are frequently used for the purpose of studying the airway mucin production and gene expression ${ }^{11-13}$.

\section{Materials and Methods}

\section{Materials}

All the chemicals and reagents used in this experiment including chrysin (purity, 95.0\%) were purchased from Sigma (St. Louis, MO, USA) unless otherwise specified.

\section{Cell culture}

NCI-H292 cells, a human pulmonary mucoepidermoid carcinoma cell line, were purchased from the American Type Culture Collection (ATCC, Manassas, VA, USA) and cultured (seeding density, $1 \times 10^{4}$ cells/ well in 24 well plate) in RPMI 1640 supplemented with $10 \%$ fetal bovine serum (FBS) in the presence of penicillin (100 units/mL), streptomycin $(100 \mu \mathrm{g} / \mathrm{mL})$ and HEPES $(25 \mathrm{mM})$ at $37^{\circ} \mathrm{C}$ in a humidified, $5 \% \mathrm{CO}_{2} / 95 \%$ air, water-jacketed incubator. For serum deprivation, confluent cells $\left(5 \times 10^{5}\right.$ cells/well in 24 well plate) were washed twice with phosphate-buffered saline (PBS) and recultured in RPMI 1640 with $0.2 \%$ FBS for 24 hours.

\section{Treatment of cells with chrysin}

After 24 hours of serum deprivation, cells were pretreated with chrysin $(1,10,100 \mu \mathrm{M})$ for 30 minutes and treated with phorbol 12-myristate 13-acetate (PMA; 10 $\mathrm{ng} / \mathrm{mL}$ ) or epidermal growth factor (EGF; $25 \mathrm{ng} / \mathrm{mL}$ ) for 24 hours in serum-free RPMI 1640. Cytotoxicity was checked by lactate dehydrogenase assay ${ }^{4}$. Chrysin was dissolved in dimethylsulfoxide, diluted in PBS and treated in culture medium (final concentrations of dimethylsulfoxide were $0.5 \%$ ). The final $\mathrm{pH}$ values of these solutions were between 7.0 and 7.4. Culture medium and $0.5 \%$ dimethylsulfoxide in medium did not affect mucin production and gene expression from NCI-H292 cells. After 24 hours, cells were lysed with buffer solution containing $20 \mathrm{mM}$ Tris, $0.5 \% \mathrm{NP}-40,250 \mathrm{mM} \mathrm{NaCl}$, $3 \mathrm{mM}$ ethylenediaminetetraacetic acid, $3 \mathrm{mM}$ ethylene glycol tetraacetic acid and protease inhibitor cocktail (Roche Diagnostics, Mannheim, IN, USA) and collected to measure the production of MUC5AC protein (in 24-well culture plate). The total RNA was extracted for measuring the expression of MUC5AC gene (in 6-well culture plate) by using reverse transcription polymerase chain reaction (RT-PCR).

\section{MUC5AC mucin analysis using enzyme-linked im- munosorbent assay (ELISA)}

MUC5AC protein was measured by using ELISA. Cell lysates were prepared with PBS at 1:10 dilution, and 100 $\mu \mathrm{L}$ of each sample was incubated at $42^{\circ} \mathrm{C}$ in a 96-well plate, until dry. Plates were washed three times with PBS and blocked with $2 \%$ bovine serum albumin for 1 hour at room temperature. Plates were again washed three times with PBS and then incubated with $100 \mu \mathrm{L}$ of 45M1, a mouse monoclonal MUC5AC antibody (1:200, NeoMarkers, Fremont, CA, USA), which was diluted with PBS containing 0.05\% Tween 20 and dispensed into each well. After 1 hour, the wells were washed three times with PBS, and $100 \mu \mathrm{L}$ of horseradish peroxidase-goat anti-mouse IgG conjugate (1: 3,000) was dispensed into each well. After 1 hour, plates were washed three times with PBS. Color re- 
action was developed with 3,3',5,5'-tetramethylbenzidine (TMB) peroxide solution and stopped with $1 \mathrm{~N}$ $\mathrm{H}_{2} \mathrm{SO}_{4}$. Absorbance was read at $450 \mathrm{~nm}$.

\section{Total RNA isolation and RT-PCR}

Total RNA was isolated by using Easy-BLUE extraction kit (Intron Biotechnology, Inc., Seongnam, Korea) and reverse transcribed by using AccuPower RT Premix (Bioneer Corp., Daejeon, Korea) according to the manufacturer's instructions. Two micrograms of total RNA was primed with $1 \mu \mathrm{g}$ of oligo(dT) in a final volume of $30 \mu \mathrm{L}$ (RT reaction). Two microliters of RT reaction product was PCR amplified in a $20 \mu \mathrm{L}$ by using Thermoprime Plus DNA polymerase (ABgene, Rochester, NY, USA). Primers for MUC5AC were (forward) 5'-TGA TCA TCC AGC AGG GCT-3' and (reverse) 5'CCG AGC TCA GAG GAC ATA TGG G-3'. As quantitative controls, primers for Rig/S15 rRNA, which encodes a small ribosomal subunit protein, a housekeeping gene that was constitutively expressed, were used. Primers for Rig/S15 were (forward) 5'-TTC CGC AAG TTC ACC TAC C-3' and (reverse) 5'-CGG GCC GGC CAT GCT TTA CG-3'. The PCR mixture was denatured at $94^{\circ} \mathrm{C}$ for 5 minutes followed by 35 cycles at $94^{\circ} \mathrm{C}$ for 30 seconds, $60^{\circ} \mathrm{C}$ for 30 seconds and $72^{\circ} \mathrm{C}$ for 30 seconds and for final extension, 1 cycle at $72^{\circ} \mathrm{C}$ for 10 minutes. After PCR, $15 \mu \mathrm{L}$ of PCR products were subjected to $1 \%$ agarose gel electrophoresis and visualized with ethidium bromide under a transilluminator.

\section{Statistics}

Means of individual group were converted to percent control and expressed as mean \pm SEM. The difference between groups was assessed using one-way ANOVA and Duncan's Multiple Range test as a post-hoc test. $\mathrm{p}$ $<0.05$ was considered as significantly different.

\section{Results}

\section{Effect of chrysin on PMA-induced MUC5AC pro- duction from $\mathrm{NCl}-\mathrm{H} 292$ cells}

As can be seen in Figure 1, chrysin significantly in- hibited PMA-induced MUC5AC production from NCIH292 cells, dose-dependently. The amounts of mucin in the cells of chrysin-treated cultures were $100 \pm 9 \%$, $207 \pm 10 \%, 199 \pm 7 \%, 168 \pm 7 \%$, and $113 \pm 2 \%$ for control, $10 \mathrm{ng} / \mathrm{mL}$ of PMA alone, PMA plus chrysin $1 \mu \mathrm{M}$, PMA plus chrysin $10 \mu \mathrm{M}$ and PMA plus chrysin $100 \mu \mathrm{M}$, respectively (Figure 1).

\section{Effect of chrysin on EGF-induced MUC5AC pro- duction from $\mathrm{NCl}-\mathrm{H} 292$ cells}

As can be seen in Figure 2, chrysin significantly inhibited EGF-induced MUC5AC production from NCIH292 cells, at the highest concentration. The amounts of mucin in the cells of chrysin-treated cultures were $100 \pm 5 \%, 302 \pm 16 \%, 280 \pm 29 \%, 285 \pm 15 \%$, and $104 \pm 6 \%$ for control, $25 \mathrm{ng} / \mathrm{mL}$ of EGF alone, EGF plus chrysin

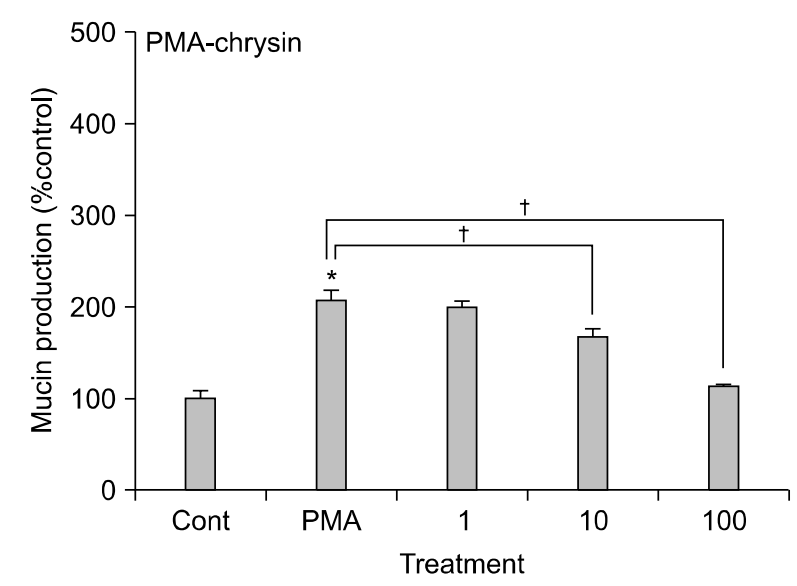

Figure 1. Effect of chrysin on phorbol 12-myristate 13acetate (PMA)-induced MUC5AC mucin production from $\mathrm{NCl}-\mathrm{H} 292$ cells were then stimulated with PMA (10 $\mathrm{ng} / \mathrm{mL}$ ) for 24 hours. Cell lysates were collected for measurement of MUC5AC mucin production by enzyme-linked immunosorbent assa. Means of individual groups were converted to percentages of the control and were expressed as mean \pm SEM. The difference between groups was assessed using one-way ANOVA and Duncan's multiple range test. $p<0.05$ was considered as statistically significant. Each bar represents a mean \pm SEM of 3 culture wells, as compared to the control, set at 100\%. ${ }^{*}$ Significantly different from control $(p<0.05) .{ }^{\dagger}$ Significantly different from PMA alone $(p<0.05)$. PMA: phorbol 12myristate 13-acetate; Cont: control. Concentration unit is $\mu \mathrm{M}$. 


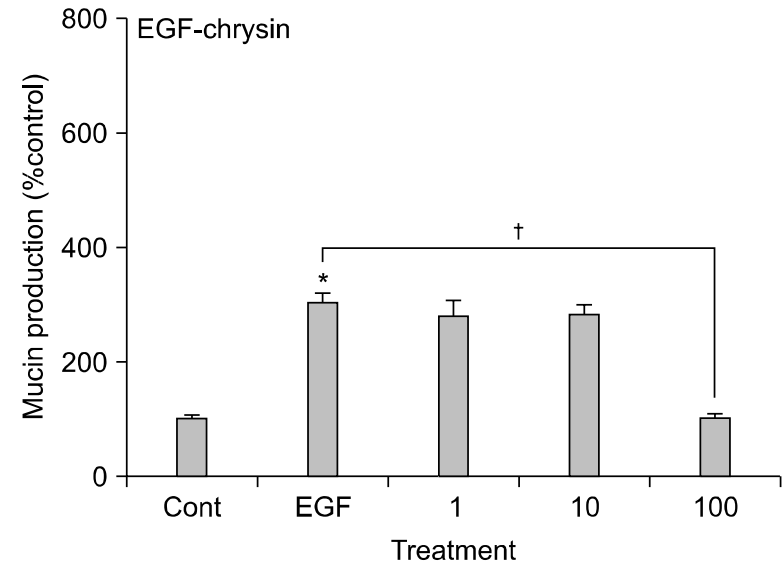

Figure 2. Effect of chrysin on EGF-induced MUC5AC mucin production from $\mathrm{NCl}-\mathrm{H} 292$ cells. NCl-H292 cells were pretreated with varying concentrations of chrysin for 30 minutes and were then stimulated with EGF $(25 \mathrm{ng} / \mathrm{mL})$ for 24 hours. Cell lysates were collected for measurement of MUC5AC mucin production by enzyme-linked immunosorbent assay. Means of individual group were converted to percentages of the control and were expressed as mean $\pm \mathrm{SEM}$. The difference between groups was assessed using one-way ANOVA and Duncan's multiple range test. $p<0.05$ was considered as statistically significant. Each bar represents a mean \pm SEM of 3 culture wells, as compared to the control, set at $100 \%$. *Significantly different from control $(p<0,05) .{ }^{\dagger}$ Significantly different from EGF alone $(p<0.05)$. EGF: epidermal growth factor; Cont: control. Concentration unit is $\mu \mathrm{M}$.

$1 \mu \mathrm{M}$, EGF plus chrysin $10 \mu \mathrm{M}$ and EGF plus chrysin $100 \mu \mathrm{M}$, respectively (Figure 2).

\section{Effect of chrysin on PMA-induced MUC5AC gene expression from $\mathrm{NCl}-\mathrm{H} 292$ cells}

As can be seen in Figure 3, MUC5AC gene expression induced by PMA from NCI-H292 cells was inhibited by pretreatment with $100 \mu \mathrm{M}$ of chrysin (Figure 3).

\section{Effect of chrysin on EGF-induced MUC5AC gene expression from $\mathrm{NCl}-\mathrm{H} 292$ cells}

As can be seen in Figure 4, MUC5AC gene expression induced by EGF from NCI-H292 cells was also inhibited by pretreatment with $100 \mu \mathrm{M}$ of chrysin (Figure 4).

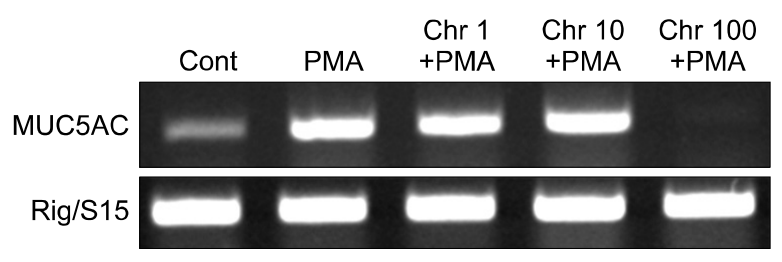

Figure 3. Effect of chrysin on PMA-induced MUC5AC gene expression from NCl-H292 cells. NCl-H292 cells were pretreated with varying concentrations of chrysin for 30 minutes and were then stimulated with PMA (10 $\mathrm{ng} / \mathrm{mL}$ ) for 24 hours. MUC5AC gene expression was measured by RT-PCR. Rig/S15 rRNA, which encodes a small ribosomal subunit protein, a housekeeping gene that was constitutively expressed, was used as a quantitative control. PMA: phorbol 12-myristate 13-acetate; RTPCR: reverse transcription polymerase chain reaction; Cont: control; Chr: chrysin. Concentration unit is $\mu \mathrm{M}$.

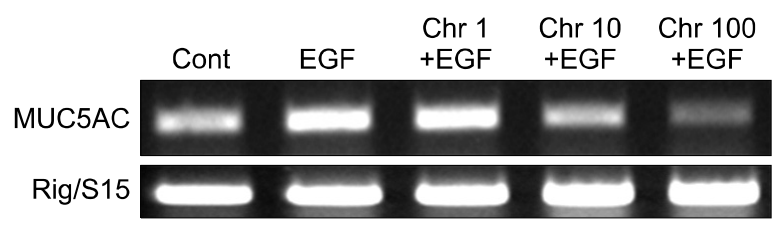

Figure 4. Effect of chrysin on EGF-induced MUC5AC gene expression from NCl-H292 cells. NCl-H292 cells were pretreated with varying concentrations of chrysin for $30 \mathrm{~min}$ and were then stimulated with EGF $(25 \mathrm{ng} / \mathrm{mL})$ for 24 hours. MUC5AC gene expression was measured by RT-PCR. Rig/S15 rRNA, which encodes a small ribosomal subunit protein, a housekeeping gene that was constitutively expressed, was used as a quantitative control. EGF: epidermal growth factor; RT-PCR: reverse transcription polymerase chain reaction; Cont: control; Chr: chrysin. Concentration unit is $\mu \mathrm{M}$.

\section{Discussion}

A potential approach to the effective control of severe pulmonary diseases involving the hyperproduction and/ or hypersecretion of airway mucus is to develop a useful pharmacological tool for regulating production and/ or secretion of mucin, the macromolecular glycoproteins present in the airway mucus. Chrysin was reported to occur in Scutellaria baicalensis Georgi ${ }^{7}$ and there are many reports with regard to the various biological effects of chrysin especially in conjunction with anti-inflammatory, anticancer and antioxidative effects ${ }^{8-10}$. 
However, as aforementioned in introduction, there are no reports about the potential effect of chrysin on mucin gene expression and production from airway epithelial cells. On the other hand, PMA was reported to stimulate the endogenous activator of protein kinase $\mathrm{C}$, diacylglycerol $^{14}$ and to be an inflammatory stimulant that can control a gene transcription ${ }^{15}$, cell growth and differentiation $^{16}$. PMA also can induce MUC5AC gene expression in NCI-H292 cells ${ }^{15}$. EGF modulated MUC5AC gene expression in the respiratory system. MUC5AC mRNA expression was increased after ligand binding to the EGF receptor and activation of the mitogen-activated protein kinase (MAPK) cascade ${ }^{17}$. Based on these reports, therefore, we investigated the effect of chrysin on PMA- or EGF-induced MUC5AC mucin gene expression and production from NCI-H292 cells, a human pulmonary mucoepidermoid cell line. As can be seen in results, chrysin suppressed the expression of MUC5AC mucin gene induced by PMA or EGF. Also, chrysin inhibited the production of MUC5AC mucin protein induced by the same inducers. Cytotoxicity was checked by lactate dehydrogenase assay and there was no cytotoxic effect of chrysin (data were not shown).

These results suggest that chrysin can inhibit mucin gene expression and production of mucin protein induced by PMA or EGF, by directly acting on airway epithelial cells. The underlying mechanism of action of chrysin on MUC5AC production and gene expression are not clear at present, although we are investigating whether chrysin act as potential regulators of the MAPK cascade after ligand binding to the EGF receptor in mucin-producing NCI-H292 cells. Also, we are investigating whether chrysin acts as a possible regulator of nuclear factor $\mathrm{kB}(\mathrm{NF}-\mathrm{kB})$ signaling pathway by examining the possible inhibition of translocation of NF-kB p65 in NCI-H292 cells after pretreatment of chrysin. Taken together, the inhibitory actions of chrysin on airway mucin gene expression and production might explain, at least in part, the traditional use of Scutellaria baicalensis Georgi, as an anti-inflammatory and anti-allergic agent for airway inflammatory diseases, in traditional oriental medicine. We suggest it is valuable both to find the nat- ural products that have specific inhibitory effects on mucin gene expression and/or production and to search the optimal chemical moieties derived from the chemical structure of chrysin which can be useful as an efficacious regulator for mucin production in hypersecretory status of diverse chronic pulmonary diseases, through future studies.

\section{Acknowledgements}

This study was financially supported by research fund of Center for Rheumatoid Arthritis and Osteoarthritis of Chungnam National University Hospital in 2011.

\section{References}

1. Voynow JA, Rubin BK. Mucins, mucus, and sputum. Chest 2009;135:505-12.

2. Yuan-Chen Wu D, Wu R, Reddy SP, Lee YC, Chang MM. Distinctive epidermal growth factor receptor/extracellular regulated kinase-independent and -dependent signaling pathways in the induction of airway mucin 5B and mucin 5AC expression by phorbol 12-myristate 13-acetate. Am J Pathol 2007;170:20-32.

3. Rogers DF, Barnes PJ. Treatment of airway mucus hypersecretion. Ann Med 2006;38:116-25.

4. Lee CJ, Lee JH, Seok JH, Hur GM, Park YC, Seol IC, et al. Effects of baicalein, berberine, curcumin and hesperidin on mucin release from airway goblet cells. Planta Med 2003;69:523-6.

5. Heo HJ, Lee SY, Lee MN, Lee HJ, Seok JH, Lee CJ. Genistein and curcumin suppress epidermal growth factor-induced MUC5AC mucin production and gene expression from human airway epithelial cells. Phytother Res 2009;23:1458-61.

6. Lee HJ, Lee SY, Lee MN, Kim JH, Chang GT, Seok JH, et al. Inhibition of secretion, production and gene expression of mucin from cultured airway epithelial cells by prunetin. Phytother Res 2011;25:1196-200.

7. Jang IM. Treatise on Asian herbal medicines. Seoul: Haksul-pyunsu-kwan in Research Institute of Natural Products of Seoul National University; 2003.

8. Du Q, Gu X, Cai J, Huang M, Su M. Chrysin attenuates allergic airway inflammation by modulating the transcription factors T-bet and GATA-3 in mice. Mol Med Report 2012;6:100-4.

9. Shao JJ, Zhang AP, Qin W, Zheng L, Zhu YF, Chen 
$\mathrm{X}$. AMP-activated protein kinase (AMPK) activation is involved in chrysin-induced growth inhibition and apoptosis in cultured A549 lung cancer cells. Biochem Biophys Res Commun 2012;423:448-53.

10. Sultana S, Verma K, Khan R. Nephroprotective efficacy of chrysin against cisplatin-induced toxicity via attenuation of oxidative stress. J Pharm Pharmacol 2012;64: $872-81$.

11. Li JD, Dohrman AF, Gallup M, Miyata S, Gum JR, Kim YS, et al. Transcriptional activation of mucin by Pseudomonas aeruginosa lipopolysaccharide in the pathogenesis of cystic fibrosis lung disease. Proc Natl Acad Sci U S A 1997;94:967-72.

12. Takeyama K, Dabbagh K, Lee HM, Agusti C, Lausier JA, Ueki IF, et al. Epidermal growth factor system regulates mucin production in airways. Proc Natl Acad Sci U S A 1999;96:3081-6.

13. Shao MX, Ueki IF, Nadel JA. Tumor necrosis factor alpha-converting enzyme mediates MUC5AC mucin ex- pression in cultured human airway epithelial cells. Proc Natl Acad Sci U S A 2003;100:11618-23.

14. Hong DH, Petrovics G, Anderson WB, Forstner J, Forstner $\mathrm{G}$. Induction of mucin gene expression in human colonic cell lines by PMA is dependent on PKCepsilon. Am J Physiol 1999;277(5 Pt 1):G1041-7.

15. Hewson CA, Edbrooke MR, Johnston SL. PMA induces the MUC5AC respiratory mucin in human bronchial epithelial cells, via PKC, EGF/TGF-alpha, Ras/Raf, MEK, ERK and Sp1-dependent mechanisms. J Mol Biol 2004; 344:683-95.

16. Park SJ, Kang SY, Kim NS, Kim HM. Phosphatidylinositol 3-kinase regulates PMA-induced differentiation and superoxide production in HL-60 cells. Immunopharmacol Immunotoxicol 2002;24:211-26.

17. Takeyama K, Dabbagh K, Shim JJ, Dao-Pick T, Ueki IF, Nadel JA. Oxidative stress causes mucin synthesis via transactivation of epidermal growth factor receptor: role of neutrophils. J Immunol 2000;164:1546-52. 